\title{
Perfis de uso de estratégias de aprendizagem de alunos em ambiente virtual
}

\author{
Vládia Maria Cabral Borges \\ Programa de Pós-Graduação em Linguística-UFC \\ vladiaborges2001@yahoo.com \\ Fco. Tarcízio C. Bevenides Júnior \\ IFCE - Campus Cedro \\ tarcizio.junior@ifce.edu.br
}

\section{Resumo}

Neste estudo analisamos o uso das estratégias de aprendizagem dos alunos da Licenciatura em Letras: Língua Inglesa da UFC/UAB com o intuito de colaborar na composição do perfil desse estudante em ambiente virtual. Para tanto, aplicamos o Inventário de Estratégias para Aprendizagem de Língua Estrangeira em 21 turmas nos 11 polos que mantêm o curso. Os dados mostram que os estudantes dessas turmas possuem um perfil de uso médio de estratégias: 77 - alunos possuem perfil médio; 34, perfil alto e 19, perfil baixo. Os dados revelam, ainda, uma queda no uso de estratégias conforme contrastamos turmas mais antigas às mais recentes no curso. $\mathrm{O}$ ano de ingresso no curso mostrou-se inversamente proporcional ao nível de uso de estratégias indicado pelo instrumento de pesquisa. Com as leituras desenvolvidas durante esta pesquisa, em virtude da proximidade de conceitos, enxergamos a possibilidade de considerarmos as estratégias de aprendizagem como categoria de medição de níveis de autonomia de aprendizagem. Isto é, passamos a conceber as estratégias de aprendizagem como um elemento mensurável que pode indicar graus de autonomia, além de ser um dos mecanismos de desenvolvimento de autonomia de aprendizagem.

Palavras-chaves: educação a distância; estratégias de aprendizagem; autonomia de aprendizagem.

\section{Abstract}

This study analyzed the learning strategies used by distance learners of English as a Foreign Language in virtual environments (UFC/UAB) in order 
to identify the different profiles of users of learning strategies. For this purpose, a Brazilian translation of the Strategy Inventory for Language Learning was used with 21 groups of students of 11 different counties in the state of Ceará. Data analysis indicated that, in general, the students could be characterized as medium users of strategies - 77 (seventy-seven) students are classified at the medium range of use, 34 (thirty-four) at the high range and 19 (nineteen) at the low range. Results also pointed out that the use of strategies decreased as students advanced in the program. Based on the results of this study, it is suggested that learning strategies be used as a category for measuring levels of learning autonomy, rather than just as one of the mechanisms for the development of autonomy in learning.

Key-words: Distance Education; Learning Strategies; Learning Autonomy.

\section{Introdução}

$\mathrm{O}$ avanço e o acesso às tecnologias da informação e comunicação (TICs) provocam mudanças em diversos setores da sociedade - entre eles, a educação ${ }^{1}$. Aprender deixa de ser uma atividade restrita a ambientes físicos, como escolas e universidades, e passa a ocupar também o ambiente virtual.

No Brasil, com o estímulo do governo à implementação da modalidade a distância, conforme a Lei de Diretrizes e Bases da Educação Nacional ( $n^{\circ}$ 9.394/96), e por meio do Decreto 5.800, de 8 de junho de 2006, instituiu-se o sistema Universidade Aberta do Brasil - UAB. Tal manobra visa a expandir e a interiorizar a oferta de cursos e de programas de educação superior no país, além de atender às necessidades do sistema básico de educação, principalmente, por meio da formação e da capacitação dos profissionais nessa área. Assim, para atender aos objetivos estipulados no decreto, foram estabelecidas parcerias entre instituições federais de ensino e a UAB.

Um exemplo dessa parceria é firmado com a Universidade Federal do Ceará (UFC). Atualmente, nove cursos são mantidos pelo instituto UFC virtual em 27 polos no estado. A instituição estima que mais de cinco mil alunos sejam beneficiados. Desses nove cursos, sete são licenciaturas: Letras Inglês, Letras Português, Letras Espanhol,

\footnotetext{
${ }^{1}$ Para um entendimento mais detalhado sobre o impacto dessas mudanças em nossa sociedade, ver, entre outros, Lévy (1993); Lemos (2002); Morin (2006). 
Química, Física, Matemática e Pedagogia. Os outros são: Bacharelado em Administração, precursor do Programa, em 2006, e Bacharelado em Administração - Gestão Pública. ${ }^{2}$.

Por conta da relevância que o contexto de ensino a distância tem alcançado na forma digital, estudos se fazem cada vez mais necessários. Por isso, neste trabalho, analisamos a utilização de estratégias de aprendizagem (EA) dos alunos da Licenciatura Semipresencialem Letras: Língua Inglesa da UFC/UAB. Para alcançar esse objetivo, aplicamos a tradução (PAIVA 1998) do Strategy Inventory for Language Learning (Inventário de Estratégias para Aprendizagem de Língua) de Oxford (1990). Hipotetizamos que, por se tratar de uma modalidade de ensino que pressupõe maior autonomia de aprendizagem, encontraríamos alto nível de utilização de EA.

Esperamos, com esta investigação, ajudar a traçar o perfil do estudante da Educação a Distância (EaD) intermediada por ambiente virtual de aprendizagem (AVA). Com base no contexto local desta pesquisa e com a leitura de demais estudos dessa área, buscamos entender mais detalhadamente a configuração da modalidade EaD nos dias atuais.

\section{A EaD, a autonomia e as estratégias de aprendizagem}

Uma das principais características da $\mathrm{EaD}$ relaciona-se à autonomia de aprendizagem demandada dos estudantes que por ela optam (BELLONI, 1999). Em virtude disso, o papel do aluno ativo e a concepção da aprendizagem como uma atividade que requer ação (contrária a uma concepção de ensino que se estabelece na passividade do aprendiz), são amplamente estimulados, e, sobretudo, são primordiais na modalidade em questão.

Em conformidade com isso está a forma de pensar o ensino de línguas, segundo pesquisadores a exemplo de Walker (2001). Segundo a autora afirma, versatilidade e flexibilidade são necessidades tanto do trabalho, quanto das demais esferas de nosso mundo, visto que a sociedade demanda tanto uma variedade de habilidades transferíveis

\footnotetext{
${ }^{2}$ Para mais informações sobre a parceria UFC/UAB, consultar http://www.virtual.ufc.br/portal/instituicao.aspx

Horizontes de Linguística Aplicada, ano 11, n. 1, jan./jun. 2012
} 
em meio às diversas situações nas quais indivíduos podem vir a se encontrar, quanto atitude e potencial para desenvolver e modificar tais habilidades. Faz-se necessário que o aluno tome a responsabilidade de sua aprendizagem para si, sendo ele próprio o responsável por gerenciá-la. Para tanto, essa autora mostra a necessidade de abordagens de ensino e de aprendizagem que promovam o aumento do nível de consciência dos aprendizes em relação às habilidades e às estratégias utilizadas na aprendizagem de línguas. Ela enxerga, por conta disso, no trabalho com as Estratégias de Aprendizagem, um grande potencial para o ensino no contexto atual.

Do mesmo modo, outros estudos têm atrelado forte destaque ao que se entende por autonomia de aprendizagem. Além da possibilidade de sucesso que a autonomia oferece ao aluno contra a distância e a falta do contato físico, ela contribui para que o próprio aluno busque soluções às suas necessidades.

Muitos autores dedicaram grande atenção à autonomia no campo do ensino de língua. Holec (1981, p.3), a definiu como a "capacidade de se responsabilizar pela própria aprendizagem", apontando que ela se caracteriza pelos seguintes aspectos: determinar objetivos; definir conteúdos e progressões; selecionar métodos e técnicas para serem usados; monitorar o processo de aquisição e avaliar o que foi adquirido. Little (1996, p.23), não muito diferentemente de Holec, a define como: "capacidade de auto-direção no planejamento, monitoramento e avaliação de atividades de aprendizagem"4. E Benson (2007, p. 70) afirma que "O aprendiz autônomo é aquele que constrói seu conhecimento a partir de experiência direta, e não aquele que responde à instrução de alguém".

Já White (2003) indica que a autonomia vem sendo considerada, ao mesmo tempo, central e problemática na aprendizagem de línguas a distância. Para ela essa modalidade oferece aos alunos novas oportunidades, ou exigências, para o desenvolvimento da

\footnotetext{
3 “ability to take charge of one's own learning” (Esta e demais traduçõs neste trabalho são de nossa autoria).

4 “ability to take responsibility to plan, implement, monitor and evaluate his/her learning[...]"

5 "The autonomous learner is one that constructs knowledge from direct experience, rather than one who responds to someone's instructions." 
autonomia. Uma das abordagens de que trata a autora em seu trabalho e que ajuda a desenvolver a capacidade autônoma dos alunos é baseada no desenvolvimento de estratégias e no treinamento dos estudantes por meio do design de materiais didáticos.

Walker (2001), Wang (2002), White (2003) e outros autores têm indicado as EA como mecanismos para promover a autonomia de aprendizagem. Nesse sentido, a importância que as EA desempenham na autonomia de estudo é amplamente aceita. Contudo, apesar das várias definições e das conceituações de autonomia, o problema que parece persistir é a falta de critérios, ou de parâmetros, para que se possa medir de forma mais simples e menos demorada a autonomia de aprendizagem.

Ao mudar essa perspectiva que enxerga as EA como um dos mecanismos para promover a autonomia, questionamos: Não seriam as $\mathrm{EA}$, na realidade, aquilo que deveríamos medir para avaliar a autonomia de aprendizagem?

Nesse sentido, pensamos ser necessário trabalhar a relação entre as EA e a autonomia, de forma a investigarmos se EA e sua utilização se configuram como meio para avaliar o grau de autonomia dos aprendizes e, assim, chegarmos a uma compreensão mais ampla do que se entende por "autonomia de aprendizagem". Pois, ao definir autonomia de aprendizagem como "a capacidade de se responsabilizar pela própria aprendizagem” (HOLEC, 1981, p.3), o processo que nos levaria a atingir/desenvolver tal capacidade passaria pela utilização de estratégias tomadas em direção a auto-aprendizagem, já que, conforme afirmado por Oxford (1989), as EA caracterizam-se por comportamentos ou processos mentais específicos que alunos usam para promover seu próprio aprendizado.

Essa definição das EA que Oxford (1989) apresenta possibilita estabelecer uma relação ainda mais estreita entre essas duas concepções. Assim, esses comportamentos e processos mentais, portanto as EA propriamente ditas, são exatamente o que há de concreto naquilo que devemos medir com intuito de avaliarmos a autonomia de aprendizagem.

Isso ajuda a responder a uma pergunta que nos tem inquietado no campo da educação a distância: Como medir/avaliar a autonomia de aprendizagem de forma mais rápida e eficiente? A reposta a essa 
pergunta seria então: por meio da análise do uso de EA. Em outras palavras, pelos "comportamentos ou processos mentais específicos que alunos usam para promover seu próprio aprendizado".

Dessa forma, defendemos que as estratégias agrupadas por Oxford e o instrumento por ela desenvolvido para medi-las podem ser considerados uma forma de avaliar a própria autonomia da aprendizagem. Embora acreditemos que esse instrumento possa funcionar como indicador da autonomia no desenvolvimento de uma língua, defendemos que as EA elencadas nesse instrumento, especialmente para EaD, devam passar por reorganizações e novas estratégias devam ser inclusas.

\section{Estratégias de aprendizagem}

Estudantes de língua têm muito a ganhar com uma compreensão mais profunda das EA (OXFORD, 1990). As pesquisas sobre as definições e o uso dessas estratégias, consideradas como um dos fatores mais eficazes (OXFORD, 2003) para determinar o sucesso na aprendizagem de uma língua, são abundantes. No entanto, pouco se sabe sobre as EA aplicadas ao ensino intermediado por AVA. Pelo fato de tais ambientes serem recentes, ainda poucos estudos são dedicados à área no Brasil. Apesar disso, encontramos, nas EA, uma abordagem que fortemente condiz com o AVA. Acreditamos que estudos que aliem as EA ao ensino são de grande benefício à $\mathrm{EaD}$, que ganha cada vez mais relevância.Muitos autores trabalharam com a conceituação de EA (O’MALLEY et al, 1985; OXFORD, 1990; DÖRNYEI, Z.; SKEHAN, 2003) desde que Rubin (1975) começou a estudá-las. Para a autora, as EA "são técnicas ou mecanismos que os alunos podem usar para adquirir conhecimento" (p.43). Ao observar o que bons aprendizes de língua faziam para obter sucesso, Rubin (1975) construiu uma lista das estratégias típicas dos bons alunos, e as dividiu em três grupos: comunicativas, sociais e afetivas. A partir de então, muitos pesquisadores se voltaram para essa direção (HOSENFELD, 1976; NAIMAN et al, 1978), chamando atenção para o fato de que é possível

\footnotetext{
6 "[...] techniques or devices which a learner may use to acquire knowledge".

64 Horizontes de Linguística Aplicada, ano 11, n. 1, jan./jun. 2012
} 
ajudar os alunos a tomarem a frente do próprio aprendizado. Esses estudos chegavam a divergir bastante, a ponto de O'Malley et al (1985) descreverem a situação da época como confusa e apontarem a falta de consenso como uma das razões para tal confusão.

Oxford (1990), por meio de uma revisão da literatura, reuniu um grande número de EA. Ele concebeu as estratégias como "passos tomados pelo aluno para melhorar o próprio aprendizado"7 (p.1) e formulou o primeiro instrumento para medir a utilização dessas estratégias. De acordo com Oxford e Burry-Stock (1995), apesar da existência de escalas com o mesmo propósito, o instrumento de Oxford continua sendo o mais amplamente empregado.

Para a formulação de seu instrumento, Oxford agrupou as EA em dois grandes conjuntos: estratégias diretas e estratégias indiretas. Na metáfora de Oxford, as estratégias diretas são atores de teatro, que realizam/dramatizam a peça. Já as indiretas são diretores, que organizam, guiam, checam, corrigem, treinam, encorajam e estimulam. Dessa forma, as diretas trabalham "com a língua propriamente dita numa variedade de tarefas e situações específicas" (OXFORD, 1990, p. 14). As estratégias indiretas estão relacionadas ao gerenciamento da aprendizagem. Por tanto, esse grupo é composto pelas estratégias de coordenação do processo de aprendizagem. Para Oxford, ambos os grupos são igualmente importantes.

Por sua vez, esses dois conjuntos agrupam outros subconjuntos. As estratégias diretas agrupam três subconjuntos: 1) estratégias de memória, que ajudam a estocar e recuperar informação, por exemplo, o agrupamento de informação e o mapeamento semântico; 2) estratégias cognitivas, que ajudam a entender e produzir a língua de diferentes formas, por meio, por exemplo, da inferência e da recombinação de elementos e 3) estratégias de compensação, que ajudam a usar a língua apesar das lacunas no conhecimento.

As estratégias indiretas também possuem três subconjuntos: 1) estratégias metacognitivas, que ajudam a controlar o processo cognitivo, ou seja, são as estratégias que coordenam o processo de aprendizagem pela autoavaliação e pelo planejamento, por exemplo; 2) estratégias afetivas, que são ligadas a fatores emocionais, a saber, o

\footnotetext{
7 “[...] steps taken by students to enhance their own learning".

8 “ [...] with the language itself in a variety of specific tasks and situations.

Horizontes de Linguística Aplicada, ano 11, n. 1, jan./jun. 2012
} 
monitoramento do grau de nervosismo, e 3) estratégias sociais, que ocorrem na interação com o outro. Ao todo, 62 estratégias de aprendizagem foram identificadas e organizadas por Oxford (1990) ${ }^{9}$.

Outro ponto importante é que, segundo Oxford, as EA, entre outras características, têm o principal objetivo focado na aprendizagem (da língua) e, assim, provocam o surgimento de novos papéis para os professores e possibilitam maior autogerência para os aprendizes ${ }^{10}$. Indiscutivelmente, essas são características capazes de formar alicerces sólidos para uma $\mathrm{EaD}$ de qualidade, ainda mais quando, como a própria autora afirma, as estratégias podem ser ensinadas em consonância com outros conteúdos e abordagens; portanto, sem excluílos, apenas somando.

\section{Metodologia}

Nesta pesquisa buscamos identificar os perfis de uso de EA entre os alunos de EaD, e propusemo-nos, assim, a estudarmos as EA utilizadas por aprendizes de inglês como língua estrangeira na Licenciatura Semipresencial em Letras: Língua Inglesa da UFC/UAB. Para tanto, aplicamos o Inventário de Estratégias para Aprendizagem de Línguas (IEALE) (PAIVA, 1998) e analisamos os resultados. Nesta seção, apresentamos o contexto da pesquisa, caracterizamos os participantes envolvidos e descrevemos os procedimentos e o instrumento utilizados para a coleta de dados.

\subsection{Contexto da pesquisa}

O curso em EaD que serve de contexto para o estudo realizado, Licenciatura Semipresencial em Letras: Língua Inglesa da UFC/UAB, é ofertado desde 2008. No entanto, inicialmente, apenas os polos das cidades de Quixadá e Meruoca contavam com essa licenciatura. Atualmente, 11 polos (Aracati, Beberibe, Brejo Santo, CaucaiaJurema, Caucaia-Sede, Caucaia-Icaraí, Itapipoca, Maranguape, Meruoca, Piquet Carneiro e Quixadá) oferecem essa formação. O curso

\footnotetext{
${ }^{9}$ Para acesso ao conjunto e organização das EA, consultar Oxford (1990).

${ }^{10}$ Consultar Oxford (1990) para um detalhamento das características chaves das EA. 66 Horizontes de Linguística Aplicada, ano 11, n. 1, jan./jun. 2012
} 
integraliza 2.888 horas em dez semestres. Dessa carga horária, oitenta por cento se dá de forma virtual intermediada pelo AVA Solar, desenvolvido pela própria UFC. A carga horária restante realiza-se presencialmente, por meio de aulas (também chamadas "encontros presenciais"). Tais encontros ocorrem sempre à noite no polo de apoio presencial, uma extensão da universidade.

\subsection{Participantes}

Para atingirmos o maior número possível de participantes, trabalhamos com os alunos que ingressaram em 2007.2, 2008.2, 2009.2 (ano e semestre), ativos no Curso de Letras: Língua Inglesa da UFC/UAB no semestre de 2011.1. Destacamos que, em 2007.2, esse curso foi ofertado para apenas dois polos (Quixadá e Meruoca) e, em 2008.2 e 2009.2, para onze polos, inclusive para os dois polos originais.

De acordo com a Secretaria Acadêmica da Instituição ${ }^{11}$ há 49 alunos na turma 2007.2, cento e sessenta na turma 2008.2 e 178 na turma 2009.2, totalizando 387 alunos. A tentativa inicial foi aplicar tal inventário com todos os alunos dessas turmas nos 11 polos que oferecem o curso. Infelizmente, isso não foi possível. Além disso, não foi possível aplicar o IEALE com o polo de Caucaia-Jurema na turma 2008.2 e com os polos de Aracati e Brejo Santo na turma 2009.2. Com isso, o número total de participantes de nosso trabalho foi cento e trinta, distribuídos da seguinte forma: oitenta participantes de 2009.2, quarenta e um de 2008.2 e nove de 2007.2.

\subsection{Procedimentos de coleta dos dados}

Os dados foram obtidos por meio de respostas dos alunos ao Inventário de Estratégias para Aprendizagem de Línguas (IEALE). Em virtude de os encontros presenciais acontecerem simultaneamente, o que inviabiliza a aplicação do inventário pelo próprio pesquisador, foi necessário recorrer ao auxílio dos tutores de disciplinas, sem os quais essa pesquisa não seria possível. Esses tutores foram instruídos a aplicar o IEALE (PAIVA, 1998) com os respectivos alunos.

${ }^{11}$ Dados extraídos do sistema de gerenciamento de matrícula - Módulo Acadêmico.

Horizontes de Linguística Aplicada, ano 11, n. 1, jan./jun. 2012 


\subsection{Instrumento}

O referido instrumento foi uma tradução, mais precisamente a de Paiva $(1998)^{12}$, do amplamente conhecido SILL - Strategy Inventory for Language Learning de Rebecca Oxford (1990).

O IEALE se divide originalmente em duas versões, uma para aprendizes de língua estrangeira, cuja língua nativa é inglês (composta de oitenta itens, e uma para aprendizes de inglês como segunda língua ou língua estrangeira cinquenta itens. Ambos usam a escala Likert, de um a cinco para indicar a concordância do participante em relação à estratégia descrita. Para cada descrição, o participante deve atribuir um dos seguintes valores: 1 - "nunca ou quase nunca verdadeira"; 2 "normalmente não verdadeira"; 3 - "de certa forma verdadeira"; 4 "normalmente verdadeira"; 5 - "sempre ou quase sempre verdadeira".

O resultado do IEALE é obtido com a média dos valores atribuídos aos itens do inventário e revela um alto, médio ou baixo uso das EA. O perfil médio se configura no intervalo de frequência de uso de EA de 2,5 a 3,4. Esse intervalo indica que as estratégias são utilizadas às vezes de acordo com a escala de Oxford (1990). O perfil baixo é aquele que está abaixo de 2,5, e o perfil alto está acima de 3,5.

O IEALE se divide em seis grupos de estratégias ou subescalas que se organizam com base em análise fatorial. No caso da versão para língua estrangeira, utilizada aqui, o primeiro grupo engloba as estratégias de memória, quais sejam: agrupar, rimar, associar a imagens, etc. (total de nove itens). O segundo conjunto agrupa estratégias referentes aos processos cognitivos, por exemplo: analisar, raciocinar, resumir, etc (14 itens). O terceiro grupo abarca os mecanismos de compensação em virtude de falta de conhecimento ou limitações, a saber: adivinhar significado pelo contexto, usar gestos para compensar falta de vocabulário, etc. (seis itens). O quarto grupo reúne estratégias do tipo metacognitivas, são elas: prestar atenção, procurar oportunidades de praticar, planejar, autoavaliar, etc. (nove itens). O quinto conjunto engloba as estratégias afetivas, por exemplo: autorrecompensa, autoencorajamento, redução de ansiedade, etc. (seis itens). A última parte do instrumento reúne as estratégias sociais, que

\footnotetext{
${ }^{12}$ A tradução do inventário de Oxford utilizada aqui pode ser consultada no endereço http://www.veramenezes.com/strategies.htm

Horizontes de Linguística Aplicada, ano 11, n. 1, jan./jun. 2012
} 
englobam as seguintes ações: cooperar com falantes nativos, fazer perguntas, etc. (seis itens).

\section{Análise e discussão dos dados}

Os resultados obtidos com a aplicação do Questionário IEALE permitiram-nos identificar o tipo de perfil de utilização de estratégias (baixo, médio ou alto) que prevalece, entre os cento e trinta estudantes da Licenciatura Semipresencial em Letras: Língua Inglesa pesquisados. A Figura 1 ilustra os dados obtidos com a aplicação do IEALE em relação ao número de perfis encontrados.

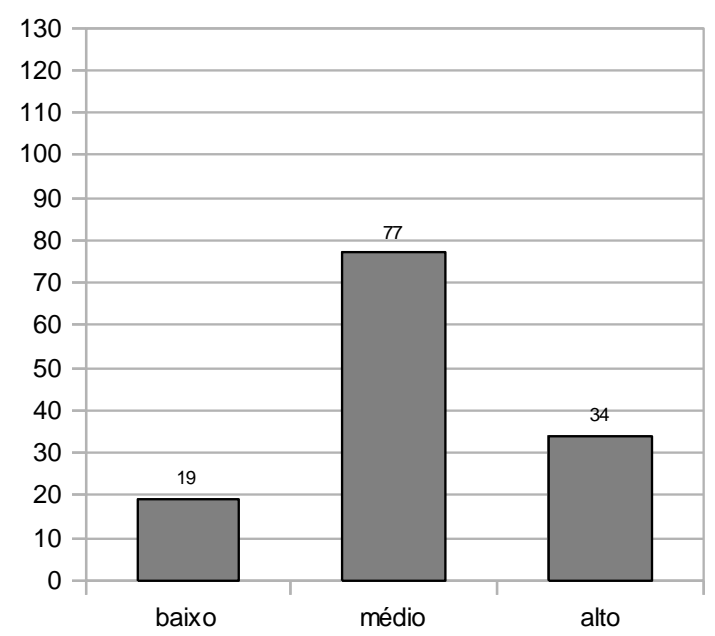

Figura 1: Resultado do IEALE em termos do número de perfis

Conforme observamos, o eixo vertical representa o número total de alunos que se voluntariaram para esta pesquisa. $\mathrm{O}$ eixo horizontal indica os perfis (respectivamente, baixo, médio e alto) de utilização de EA que o IEALE retorna como resultado. As colunas indicam a quantidade de participantes que, com a aplicação do inventário, foram enquadrados em cada um desses perfis.

Horizontes de Linguística Aplicada, ano 11, n. 1, jan./jun. 2012 
De acordo com a Figura 1, dos cento e trinta alunos com os quais trabalhamos, a maior parte, 77, enquadram-se em um perfil médio de utilização de estratégias de aprendizagem. Em termos percentuais, isso perfaz aproximadamente 59,23\% do número total de alunos. Em seguida, com 34 alunos, está o perfil alto de utilização de EA, perfazendo, aproximadamente, $26,15 \%$ do total de alunos. O menor número de alunos - 19 no total - apresenta um perfil baixo de utilização de estratégias. Em termos percentuais isso significa que apenas $14,61 \%$ dos alunos com os quais trabalhamos usam pouco o conjunto de EA reunidas por Oxford (1990).

De um modo geral, os dados indicam que os alunos deste estudo fazem uso de EA, o que nos parece apropriado às necessidades de aprendizagem em EaD. Percebemos uma aparente tendência desses alunos a darem os próprios passos em direção ao aprendizado. Os dados sugerem, ao menos, uma boa frequência de utilização das estratégias elencadas por Oxford (1990), haja vista que apenas um pequeno número desses alunos, 19 entre 130, relatam pouca utilização dessas estratégias. O ponto positivo em relação a essa boa frequência de utilização de estratégias por parte desses alunos está na correlação entre o desempenho e o uso de estratégias, já que estudos tendem a apontar que quanto maior o uso de EA, melhor o desempenho (ou maior o nível) dos alunos que as empregam (ex.: OXFORD; NYIKOS, 1989; OXFORD, 1989).

No entanto, quando se passa a considerar o ano de ingresso dos alunos no curso, constatamos uma relação que contraria o que mostram as pesquisas na área. Observe-se a Figura 2.

Nos moldes da Figura 1, na Figura 2, o eixo vertical indica o número de alunos e o eixo horizontal os perfis (respectivamente, baixo, médio e alto) de utilização de EA. As colunas indicam a quantidade de participantes que, com a aplicação do inventário, foram enquadrados em cada um desses perfis. As cores preta, cinza e branca servem para destacar a turmas as quais os alunos pertencem: respectivamente 2009.2, 2008.2 e 2007.2. 


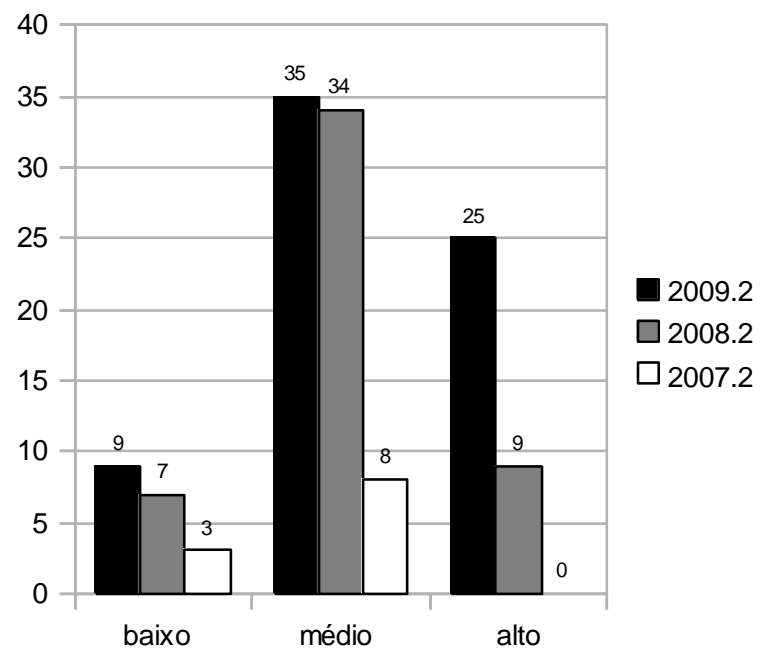

Figura 2: Tipos de perfil $X$ ano de entrada no curso

Dessa forma, ao nos concentrarmos somente na turma 2009.2 (colunas pretas), percebemos que 35 alunos, 50,72\% dos 69 da turma 2009.2, estão no perfil médio de utilização de EA; ao passo que 25 indivíduos, 36,23\% dos alunos nessa turma, têm um perfil alto de utilização de EA. Por fim, o restante, nove alunos, ou 13,04\% do total de alunos na turma 2009.2, estão classificados no perfil baixo de utilização de EA. Portanto, de forma análoga aos dados gerais anteriormente analisados, dentre os indivíduos pertencentes à turma 2009.2, o perfil médio de utilização de EA tem o maior número de sujeitos; o perfil alto foi o segundo com maior número de sujeitos e o perfil baixo com menor quantidade de alunos. Em termos percentuais, na turma 2009.2, em comparação aos dados gerais, que não levam em consideração a turma na qual os alunos se encontram no curso, há um leve aumento, de apenas $1,57 \%$ do número de alunos com perfil baixo; uma redução, com um número mais considerável, de $8,51 \%$ no número de alunos com perfil médio e um aumento, também considerável, de $10,08 \%$ no número de alunos com perfil alto. 
Ao nos concentrarmos na turma 2008.2, ou seja, observando somente as colunas cinzas, verificamos que 34 alunos, $68 \%$ do número total de cinquenta alunos nessa turma, estão no perfil médio de uso das EA, ao passo que nove sujeitos, apenas $18 \%$ dos cinquenta alunos dessa turma, estão no perfil alto de uso das EA. Por fim, nesse semestre, sete alunos, ou 14\%, relatam um perfil baixo de uso das EA.

Ao focarmos os dados obtidos na observação da turma 2009.2, notamos que, similarmente, o perfil no qual se registra a maior quantidade de sujeitos na turma 2008.2 é o perfil médio de uso das EA. Contudo, constatamos um equilíbrio, que não houve na análise dos dados da turma 2009.2, entre os perfis baixo e alto. A diferença entre esses dois perfis na turma 2008.2 é de apenas quatro por cento, ao passo que na turma 2009.2 essa mesma diferença (entre os perfis alto e baixo) é de 23,19\%. Em comparação com a turma 2009.2, em termos percentuais, o número de alunos com perfil baixo de uso de EA é menos de um por cento, ou seja, 0,96\% maior nessa turma (praticamente igual), ao passo que o número de alunos com perfil médio é $17,28 \%$ maior. Já o número de alunos com perfil alto é $18,23 \%$ menor nessa turma do que na turma de 2009.2.

Finalmente, ao observarmos a turma 2007.2, somente as colunas brancas, oito alunos, $72,72 \%$ do número total de alunos nessa turma, relatam um perfil médio de uso de estratégias. Nenhum aluno relata perfil alto. Três alunos, 27,27\%, relatam um perfil baixo de uso de EA. Da mesma forma que na análise das duas outras turmas, o perfil médio de uso de EA é, também na turma 2007.2, o que reúne a maior quantidade de sujeitos. Contudo, o perfil baixo de uso de EA passa a ocupar a segunda posição em termos de número de alunos. Em termos percentuais, percebemos um aumento no número de alunos com perfil de baixo uso de EA, aumento de 14,23\% em relação à turma $2009.2 \mathrm{e}$ de $13,27 \%$ em relação à turma 2008.2. Quanto ao perfil médio, houve um aumento de $22 \%$ em relação à turma 2009.2 e de apenas $4,72 \%$ em relação à turma 2008.2. Já no perfil alto, não houve redução. Contudo, torna-se extremamente necessário destacar que, na turma 2007.2, o número total de participantes é bem menor do que nas outras duas turmas o que, portanto, torna difícil esse tipo de comparação. 
A Figura 3 ilustra a distribuição dos percentuais dos perfis identificados com o inventário de acordo com a turma a que os alunos pertencem.

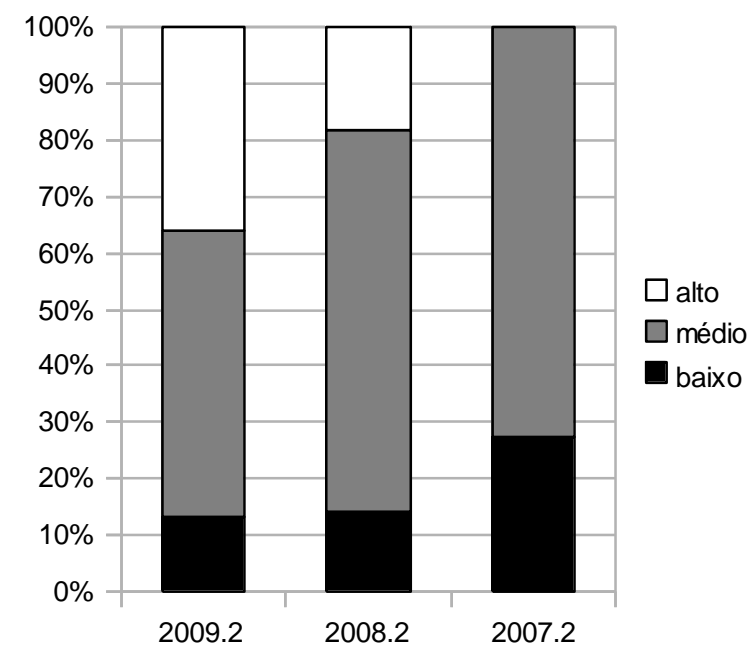

Figura 3: Distribuição dos tipos de perfis em relação às turmas a que pertencem os alunos

Conforme verificamos na Figura 3, em relação ao perfil de baixo uso de EA (coluna preta), a diferença percentual é pequena, quase não visível, entre as turmas 2009.2 e 2008.2 (0,96\%). Em relação à turma 2007.2, a diferença nesse mesmo perfil é bem mais visível (13,27\%) em comparação com a de 2008.2. Já a diferença do percentual de alunos com perfil médio (coluna cinza) é maior entre as turmas 2009.2 e $2008.2(17,28 \%)$ e muito pequena entre as turmas 2008.2 e 2007.2 (4,72\%). É interessante, embora paradoxal, observar que, conforme os alunos avançam no curso, há uma diminuição no uso de estratégias, pois o percentual de alunos com perfil alto (cor branca) diminui entre as turmas 2009.2 e 2008.2 e se extingue na turma 2007.2. Embora estudos (OXFORD; NYIKOS, 1989; OXFORD, 1989) apontem para aumento de frequência de uso de estratégias conforme aumento no tempo de estudo, nesta pesquisa evidenciou-se o contrário. 
Nossos resultados indicam que tanto na turma 2008.2., quanto na de 2007.2, o percentual de alunos com perfil médio é maior do que o da turma de 2009.2. Já em relação ao perfil alto de uso de estratégias, há um maior percentual de alunos com perfil alto na turma 2009.2 do que na turma 2008.2, que por sua vez é maior do que na turma 2007.2. A nosso ver, tais dados poderiam ser indicações, por exemplo, de que a turma 2009.2 emprega mais esforço em relação à própria aprendizagem, e, portanto, é mais autônoma, do que a turma de 2008.2.

$\mathrm{Na}$ realidade, em virtude do que conhecemos da organização e da implementação da EaD no Ceará, nossa hipótese é de que os dados aqui obtidos são reflexos de características próprias inerentes à forma como a EaD inicialmente se estabeleceu no estado. Acreditamos que os dados não se oponham, em verdade, às pesquisas que indicam que mais anos de estudo levam a perfis mais altos de uso de EA (OXFORD; NYIKOS, 1989; OXFORD, 1989). Nossa hipótese é a de que as primeiras turmas de EaD diferem das seguintes, sucessivamente, e aproximam-se do que se estabelecerá como o padrão dos alunos de EaD. Em outras palavras, atribuímos essa queda no perfil de uso de EA ao tipo de aluno pertencente a cada uma dessas turmas, que veio mudando, conforme a EaD foi estabelecida.

De um modo geral, inicialmente, a EaD atraiu alunos que já estavam afastados do ensino há bastante tempo. Muitos desses alunos já se encontravam inseridos no mercado de trabalho, à frente de suas famílias, em suma, mais ocupados no geral do que o perfil de alunos mais tradicionais que ocupam a modalidade presencial. Um grande número deles recorreu à $\mathrm{EaD}$ como uma alternativa para melhorar suas condições de vida por meio de qualificações. Dessa forma, o maior objetivo desses estudantes não seria propriamente acadêmico. A aprendizagem em si muitas vezes não estava entre suas principais metas. Ainda, a geração de alguns desses indivíduos não teve o mesmo nível de contato com o computador que as gerações mais recentes têm. Dessa forma, muitos desses encontravam-se afastados de uma cultura digital. Contudo, tal realidade foi mudando conforme novas turmas de alunos se inseriam na modalidade. Portanto, suscitamos a hipótese de que as três turmas possuem, entre outras características, níveis de autonomia distintos. E os alunos da turma 2009.2, nessa modalidade, recém-saídos do ensino médio, são um pouco mais autônomos, mais 
dinâmicos, mais motivados, mais inseridos em cultura digital e menos ocupados do que os alunos das turmas 2008.2 e 2007.2. Em suma, são alunos com mais disposição, tempo, etc. para fazer algo pela própria aprendizagem.

\section{Considerações Finais}

Para resumir os resultados obtidos neste estudo, podemos dizer que, dos cento e trinta alunos com os quais trabalhamos, a maior parte, 77 alunos, têm um perfil médio de utilização de estratégias de aprendizagem. Dessa forma, o perfil geral dos alunos do Curso de Licenciatura Semipresencial em Letras: Língua Inglesa da UFC/UAB com os quais trabalhamos se encaixa em uma categoria média de uso das EA. Os dados parecem indicar uma leve correlação entre o ano de ingresso e o uso de EA: quanto mais recente o ano de ingresso dos sujeitos de nossa pesquisa no curso, maior o uso de EA.

Nosso intuito inicial foi trabalhar com todos os alunos do curso que serviu de contexto para nossa pesquisa. Apesar dos diversos esforços, a pouca participação por parte dos alunos, e inclusive a pouca colaboração de uma minoria dos tutores à frente das disciplinas, impediram-nos de levar a termo nosso intuito original. O número de participantes, que configurou-se como uma amostra, por não representar a população total como pretendíamos, impossibilitou um resultado mais conclusivo.

Podemos sugerir, no entanto, uma forma de confirmar a hipótese de que alunos recém-ingressos na $\mathrm{EaD}$ aplicariam mais esforços na própria aprendizagem do que alunos antigos. Seria possível selecionar amostras aleatórias simples de cada uma das turmas ativas no Curso de Licenciatura Semipresencial em Letras: Língua Inglesa da UFC/UAB e aplicar, com os sujeitos selecionados, o IEALE. A amostragem aleatória daria condições para a utilização de procedimentos estatísticos mais simples, como o qui-quadrado, que nos daria a possibilidade de resultados mais conclusivos. Infelizmente, nossos resultados não podem ser generalizados.

De qualquer forma, apesar dos problemas encontrados, este estudo suscita discussões a respeito do perfil de aluno da EaD. Nossas 
indagações e proposições podem ser de ajuda na tentativa de se conhecer melhor tal aluno, principalmente nesse novo contexto a distância, próprio da era digital. Com certeza, conhecer quem são e quem foram os alunos nesse contexto é de muita importância no sentido de apontar mudanças, ou inclusive melhorias, necessárias aos processos e aos materiais tanto didáticos quanto metodológicos.

Este trabalho tem também o mérito de trazer os estudos em EA para o contexto de aprendizagem em ambiente virtual. Os resultados obtidos não são conclusivos nem podem ser generalizados, mas dão início à caracterização do aprendiz de EaD em termos de uso de EA.

Ainda, com base neste estudo fomos instigados a trabalhar com as EA e suas relações com a autonomia de aprendizagem. Trabalhos como os de Walker (2001), Wang (2002), White (2003), evidenciam as estratégias como um dos mecanismos para se atingir tal autonomia. Contudo, podemos sugerir estudos que utilizem as estratégias como categorias de análise para a avaliação da autonomia de aprendizagem. Essa ótica nos ajudaria a responder a pergunta "Como medir/avaliar a autonomia de aprendizagem de forma mais prática/rápida?” Em outras palavras, acreditamos que a análise das EA utilizadas pelos alunos pode servir a tal propósito.

\section{Referências}

BELLONI, Maria L. Educação à distância. Campinas, SP: Autores Associados, 1999.

BENSON, Philip. Teaching and researching autonomy in language learning. Harlow: Longman/Pearson Education, 2007.

BRASIL. LDB - Leis de diretrizes e bases da educação nacional. LEI No. 9.394, de 20 de dezembro de 1996. D.O.U. de 23 de dezembro de 1996.

BRASIL. Presidência da República. Decreto n. 5.800, de 8 de junho de 2006. Dispõe sobre o Sistema Universidade Aberta do Brasil - UAB. 
Disponível em: <http://www.planalto.gov.br/ccivil_03/_Ato20042006/2006/Decreto/D5800.htm> Acesso em 10 mar. 2011.

DÖRNYEI, Zoltán.; SKEHAN, Peter. Individual differences in second language learning. In Catherine Doughty and Michael Long (Eds.). Handbook of second language acquisition. Oxford: Blackwell, 2003. p. $589-630$.

HOLEC, Henri. Autonomy and foreign language learning. Oxford: Pergamon, 1981.

HOSENFELD, Carol. Learning about learning: discovering our students' strategies. Foreign Language Annals, v. 9, p. 117-129, 1976.

INSTITUTO UNIVERSIDADE VIRTUAL DA UNIVERSIDADE FEDERAL DO CEARÁ. Portal UFC. Disponível em: $\langle$ http://www.virtual.ufc.br/portal/instituicao.aspx $>$. Acesso em 15 jul. 2011.

LEMOS, André. Cibercultura: tecnologia e vida social na cultura contemporânea. Porto Alegre: Sulina, 2002.

LÉVY, Pierre. As tecnologias da inteligência: o futuro do pensamento na era da informática. São Paulo: Editora 34, 1993.

LITTLE, David. Learner autonomy and learner counseling. In: LITTLE, David; BRAMMERTS, Helmut. (Eds.). A guide to language learning in tandem via the Internet. CLCS Occasional Paper n. 46. Dublin: Trinity College, 1996. p. 23-24.

MORIN, Edgar. Os sete saberes necessários à educação do futuro. São Paulo: Editora Cortez, 2006.

NAIMAN, Neil. et al. The Good Language Learner. Research in Education Series, n. 7. Toronto: The Ontario Institute for Studies in Education, 1978. 
Perfis de uso de estratégias de aprendizagem

O’MALLEY, J. Michael. et al. Learning strategies used by beginning and intermediate ESL students. Language Learning, v. 35, n. 1, p. 21 46, 1985.

OXFORD, Rebecca L. Use of language learning strategies: A synthesis of studies with implications for strategy training. System, v. 17, p. 235$247,1989$.

Language learning strategies: what every teacher should know. Boston: Heinle \& Heinle, 1990.

Language Learning styles and strategies: an overview. 2003. Disponível em: http://web.ntpu.edu.tw/ language/workshop/read2.pdf. Acesso em: 25 set. 2010.

; BURRY-STOCK, Judith A. Assessing the use of language learning strategies worldwide with the ESL/EFL version of the strategy inventory for language learning. (SILL). System, v 23, n 1, p. 1-23, 1995.

; NYIKOS, Martha. Variables affecting choice of language learning strategies by university students. The Modern Language Journal, v. 73, n. 3, p. 291-300, 1989.

PAIVA, Vera L. M. O. Estratégias individuais de aprendizagem de língua inglesa. Letras \& Letras, v. 14, n. 1, p. 73-88, 1998.

RUBIN, Joan. What the "good language learner" can teach us. TESOL Quarterly, v. 9, n.1, p. 41-51, 1975.

WALKER, Lesley. Learning strategies and learner autonomy. In: ARTHUR, Lore; HURD, Stella. (Ed.) Supporting lifelong language learning: theoretical and practical approaches. London: CILT, 2001. p. 83-94.

WANG, Duqin. Fostering learner autonomy in college English study. Foreign Language World, v. 5, p. 17-23, 2002. 
Vládia Maria Borges e Fco. Tarcízio Júnior

WHITE, Cynthia. J. Language learning in distance education. Cambridge University Press, New York: 2003.

Recebido em: 06/01/2012

Aceito em: $\quad$ 04/12/2012

Title: Profiles of students' use of learning strategies in a virtual learning environment 
Perfis de uso de estratégias de aprendizagem 